\title{
Biomimetic System for the Application of Nanomaterials in Fluid Purification: Removal of Arsenic with Ferrihydrite
}

\author{
Kyriakos Atmatzidis, Farbod Alimohammadi, Daniel R. Strongin, and Rouzbeh Tehrani*
}

Cite This: ACS Omega 2020, 5, 5873-5880

Read Online

ABSTRACT: The use of nanomaterials has transformed fields such as medicine and electronics. However, aggregation of nanomaterials in aqueous solutions, difficult recovery of spent nano-adsorbents from reactors, and a tremendous pressure loss caused by nanoadsorbents in adsorption columns have prevented the wide-scale use of nano-adsorbents in industrial applications for water purification. An over-reliance on traditional adsorption media for fluid purification practices has slowed innovation in this field. This study serves as a proof of concept for a new approach in utilizing nano-adsorbents in water treatment. A system based on the concept of renal dialysis was used to treat a solution of arsenite using two-line ferrihydrite (Fh) under environmental conditions. The performance was compared to traditional batch

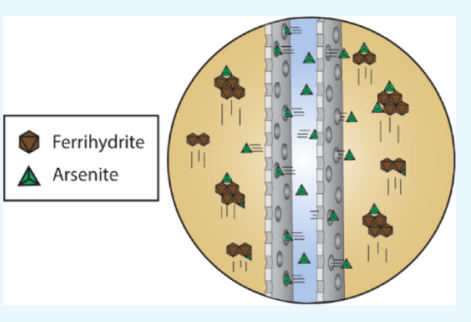
studies, and environmental variables $\mathrm{pH}$ and Eh were monitored. The system removed 67 and $91 \%$ of arsenite at 1.22 and $2.61 \mathrm{~g} / \mathrm{L}$ Fh loadings, respectively, in comparison to batch experiments that removed 82 and $94 \%$ for similar loadings. Operational conditions and the physical design of the vessel limited the extent of removal that could be obtained with the system. Design advantages, shortcomings, and required improvements are discussed.

\section{INTRODUCTION}

Adsorption has emerged as a cost-effective method for fluid purification, including water treatment. Unfortunately, largescale adsorption technologies have failed to evolve as quickly as new materials have been discovered. In the water treatment industry, much of the industry still heavily relies on activated carbon, microsized metal oxides, and ion exchange resins. Nanomaterials are not suitable for conventional fixed bed or flow-through systems. They create large pressure drops, have poor mechanical strength, and, more importantly, are difficult to separate from water. ${ }^{1}$ Although some researchers have attempted to fix nano-adsorbents onto supporting media that can be adapted to current treatment systems, this process inherently limits the utility of the material. ${ }^{2}$ Much work with nano-adsorption has remained at the laboratory stage, and translation to industrial-scale use considerably lags in comparison to other fields such as electronics and medicine. ${ }^{3}$

The concept of a hemodialyzer, which is used in medicine as a biomimetic for artificial kidneys, suggests an alternative method for the application of nanomaterials in water treatment. During hemodialysis, blood is pumped into the hemodialyzer through an inlet and is distributed into a membrane. Pressure and a concentration gradient induce mass transfer through the membrane, and waste products and excess fluid are removed as blood flows to the outlet. Simultaneously, a dialysate solution is pumped in a counterflow direction outside the membrane and carries away the waste. ${ }^{4,5}$ This same process can be adapted for the use of nanomaterials in water treatment and fluid purification in general. As a contaminated stream is passed on one side of a selective membrane, a counterflowing service fluid of nano-adsorbents is passed on the other side. As contaminants pass through the membrane, they can be picked up by fast-acting nano-adsorbents. This concept can also be applied more simply by passing a service fluid with unidirectional flow over a membrane containing a stagnant contaminant solution.

In the following proof-of-concept experiments, we demonstrate a simplified application of the hemodialyzer (renal dialysis) concept for fluid purification. A dialysis system is utilized to adsorb arsenite (as $\mathrm{H}_{3} \mathrm{AsO}_{3}$ at or near a circumneutral $\mathrm{pH}$ ) with two-line ferrihydrite $(\mathrm{Fh})$. The system's removal efficiency is assessed and compared to traditional batch experiments. Changes in environmental process variables $\mathrm{Eh}$ and $\mathrm{pH}$ are monitored and reported throughout the treatment period. The Results and Discussion section considers benefits and limitations of the system and notes areas of needed improvement. To the best of our knowledge, this is the first-ever reported application of nanomaterials in dialysis-based treatment. Motivation for the use of arsenic and $\mathrm{Fh}$ as a model contaminant and nanoadsorbent, respectively, follows.

Arsenic is a naturally occurring metalloid that is both abundant and ubiquitous in the Earth's crust and is released in large quantities through industrial processes and agricultural

Received: December 3, 2019

Accepted: February 27, 2020

Published: March 10, 2020 


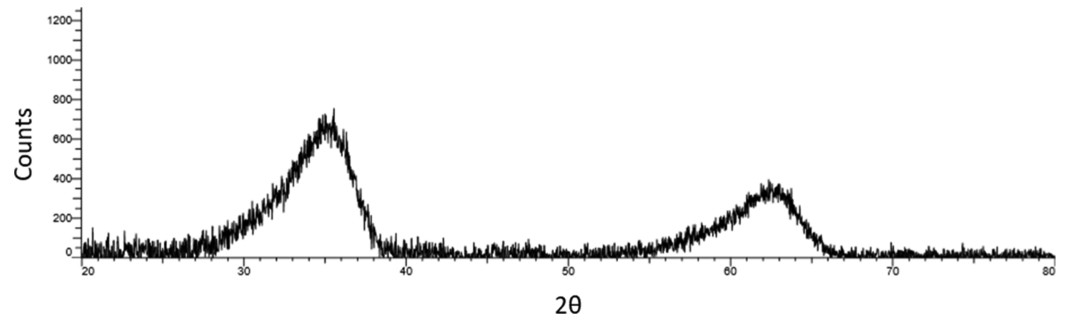

Figure 1. Powder XRD diffractogram ( $\mathrm{Cu} \mathrm{K} \alpha \lambda=1.54060)$ of Fh synthesized by the SDM.

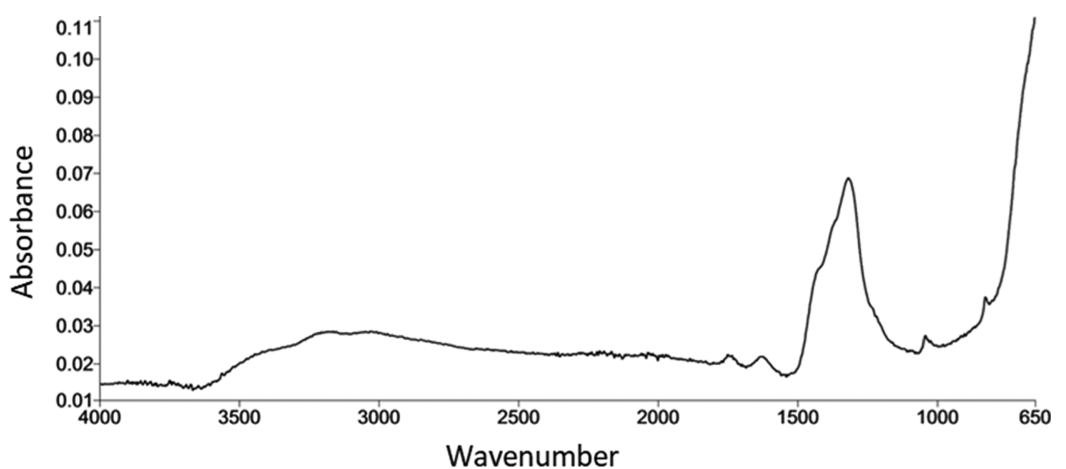

Figure 2. ATR-FTIR spectrum of Fh synthesized by the SDM.

applications. ${ }^{6,7}$ Exposure to arsenic occurs through contaminated food, water, and air, and the risk of exposure and potential adverse health effects have been well documented. ${ }^{7-10}$ In the environment, arsenic combines with other elements and is found in several organic and inorganic forms, ${ }^{11}$ but arsenite is the most mobile and toxic. ${ }^{12,13}$ Adsorption of arsenic onto iron oxide minerals has been investigated over the years, ${ }^{14-17}$ and Fh, a naturally occurring nanomaterial and precursor to more crystalline iron oxides, ${ }^{18,19}$ has gained substantial interest. Fh is an intrinsically nanodimensional material (2-3 nm diameter) with a BrunauerEmmett-Teller (BET) surface area between 133 and $320 \mathrm{~m}^{2} /$ g, a high adsorption capacity, ${ }^{20-24}$ and strong binding to arsenic via inner-sphere ${ }^{2} \mathrm{C}$ and ${ }^{2} \mathrm{E}$ complexes, ${ }^{24,2}$ which make it a desirable nano-adsorbent.

\section{RESULTS AND DISCUSSION}

Characterization of Fh. Fh used in the experiments was prepared using a solvent deficient method (SDM). The X-ray diffraction (XRD) diffractogram in Figure 1 identifies the material as two-line Fh. The two broad peaks at 35 and $62.5^{\circ}$ that define two-line $\mathrm{Fh}$ are in good agreement with Bragg peaks reported in the literature ranging from 34 to $35^{\circ}$ and 61 to $63^{\circ} 2 \theta$, respectively, for $\mathrm{Cu} \mathrm{K} \alpha(\lambda=1.54060)$ irradiation. $^{19,22,26-31}$ The Fourier transform infrared (FTIR) spectrum in Figure 2 shows broad bands at 3400 and 3200 $\mathrm{cm}^{-1}$ attributable to structural hydroxide and sorbed $\mathrm{H}_{2} \mathrm{O}$, respectively. A series of peaks between 1750 and $800 \mathrm{~cm}^{-1}$ are associated with the various vibrational modes of bicarbonate and carbonate, which are formed from adsorbed $\mathrm{CO}_{2} \cdot{ }^{32-35} \mathrm{As}$ indicated by the white circle-bounded particles in the transmission electron microscopy (TEM) image of Figure $3 \mathrm{~A}$, the material is composed of individual particles with diameters less than $10 \mathrm{~nm}$ in size. Furthermore, the scanning electron microscopy (SEM) image in Figure 3B shows that the material is aggregated with smaller particles of varying size and shape embedded into larger particles. BET measurements
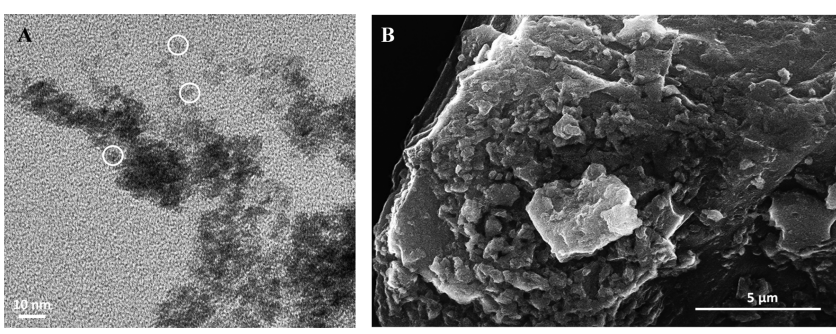

Figure 3. TEM (A) and SEM (B) images of Fh after synthesis by the SDM. Single particles of Fh are bounded by white circles within the TEM image for size comparison.

show that $\mathrm{Fh}$ has a high surface area of $192 \mathrm{~m}^{2} / \mathrm{g}$, falling within the lower end of values found in the literature and lower than the $250 \mathrm{~m}^{2} / \mathrm{g}$ reported by Smith et al. ${ }^{26}$ However, different batches produced using the SDM yielded surface areas varying from 192 to $329 \mathrm{~m}^{2} / \mathrm{g}$ (Table S1), and special attention should be paid to the reported surface area values (Table S2). The observed correlation between the adsorbent age and measured surface area is discussed in the Supporting Information.

Dialysis System Performance. The mechanism of arsenite removal using the dialysis system is illustrated in Figure 4. A service fluid composed of Fh particles suspended in water by mixing was pumped continuously through the bottom inlet of a tube containing a membrane. Arsenite that was manually added into the lumen of the membrane diffused into the service solution over time and most adsorbed onto Fh particles flowing through the tube.

Figure 5A,B shows the dialysis system's removal of arsenite using 1.22 and $2.61 \mathrm{~g} / \mathrm{L}$ Fh loadings. The amounts of arsenite in the lumen and in the service fluid over time are presented as mass fractions of the total arsenite added to the lumen initially. Total arsenite for the 1.22 and $2.61 \mathrm{~g} / \mathrm{L}$ loadings was 20.2 and $25.1 \mathrm{mg}$, respectively. During treatment, the amount of arsenite in the lumen decreased by $95 \%(1.22 \mathrm{~g} / \mathrm{L} \mathrm{Fh})$ and $98 \%(2.61$ $\mathrm{g} / \mathrm{L} \mathrm{Fh}$ ), and the amount of arsenite in the service fluid slowly increased as arsenite was both distributed into the service fluid 


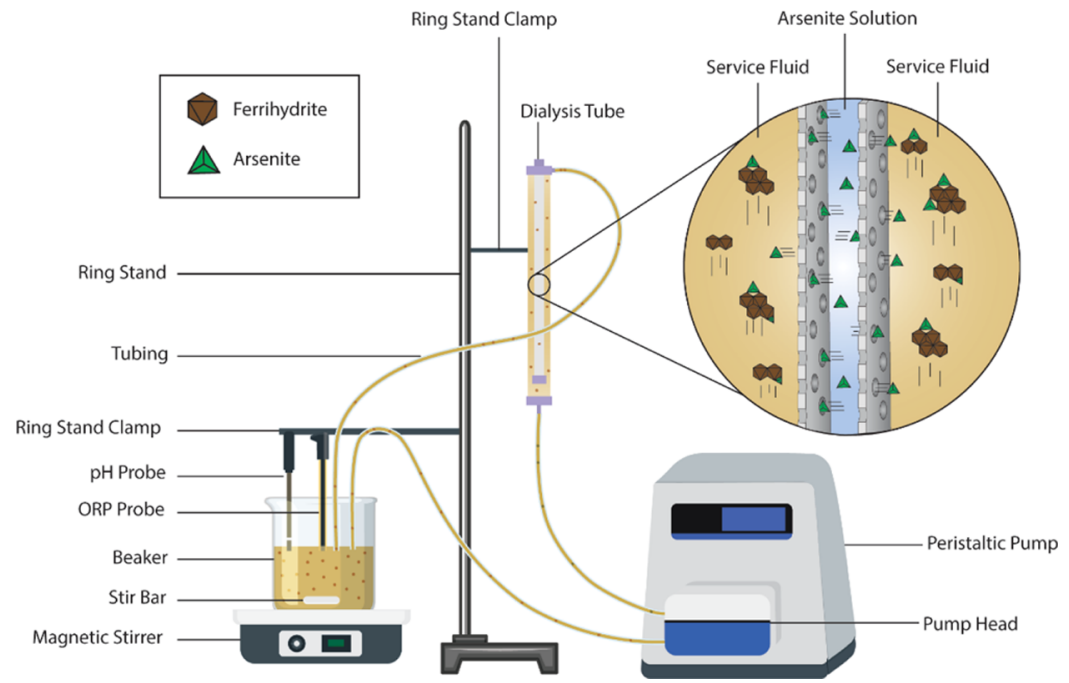

Figure 4. Proposed dialysis system for the application of nanomaterials in fluid purification. Arsenite solution added to the lumen of the membrane diffuses into the service solution and is adsorbed by Fh particles that are continuously flowing up through the dialysis tube.
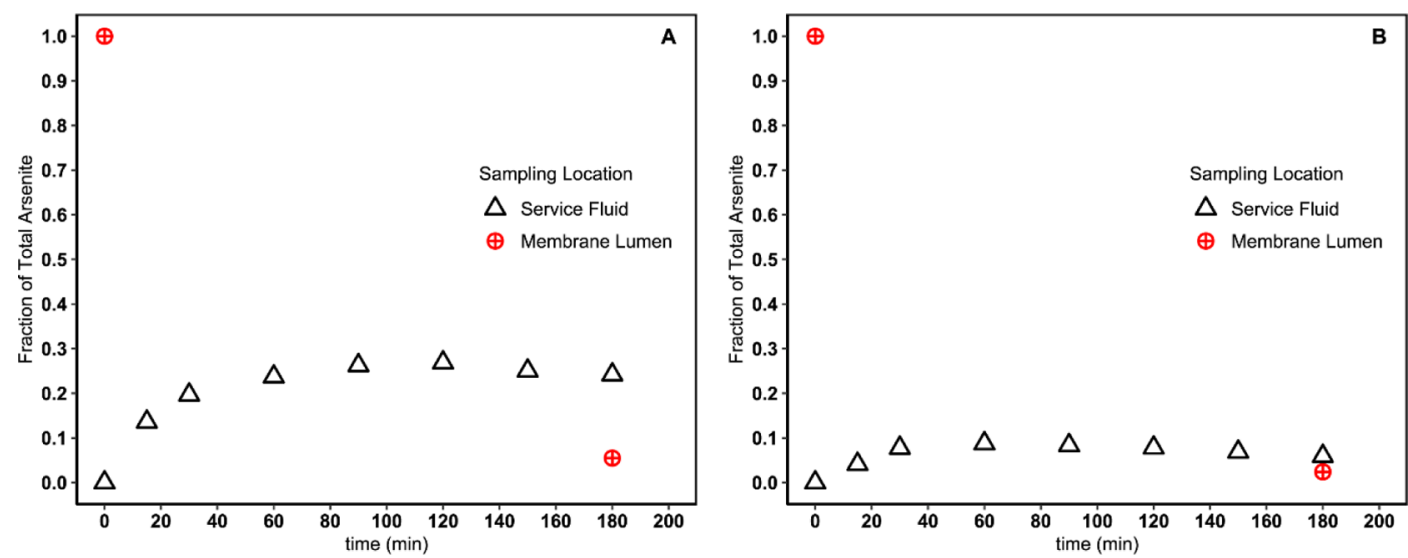

Figure 5. Residual arsenite in the membrane lumen and service fluid of the system over time for 1.22 (A) and $2.61 \mathrm{~g} / \mathrm{L}$ (B) adsorbent loadings. The amount of arsenite is presented as a mass fraction of total arsenic.
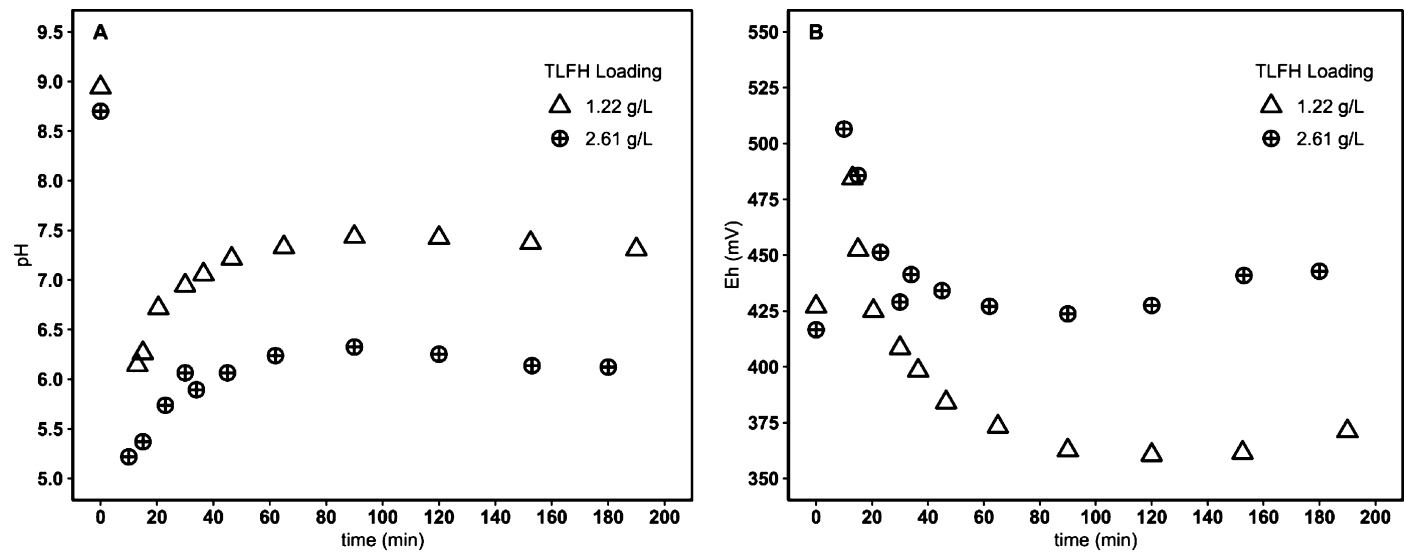

Figure 6. Changes in $\mathrm{pH}(\mathrm{A})$ and $\mathrm{Eh}(\mathrm{B})$ of the service fluid with 1.25 and $2.68 \mathrm{~g} / \mathrm{L}$ Fh loadings.

and adsorbed by Fh. By the end of $3 \mathrm{~h}$, adsorption was complete as the concentration in the service fluid had plateaued. However, the $2.61 \mathrm{~g} / \mathrm{L}$ Fh loading had a lower residual mass of arsenite in the service fluid, indicating that a greater portion of arsenite was adsorbed.

Adsorbed arsenite was calculated using a mass balance on total arsenite according to eq 1 .

$$
\mathrm{RE}_{\mathrm{sys}}=\frac{C_{\mathrm{i}}^{\mathrm{LS}} V_{\mathrm{i}}^{\mathrm{LS}}-\left(C_{\mathrm{f}}^{\mathrm{LS}} V_{\mathrm{f}}^{\mathrm{LS}}+V_{\mathrm{s}} \sum_{n=1}^{m-n \geq 1} C_{n}^{\mathrm{SF}}+C_{m}^{\mathrm{SF}} V_{\mathrm{f}}^{\mathrm{SF}}\right)}{C_{\mathrm{i}}^{\mathrm{LS}} V_{\mathrm{i}}^{\mathrm{LS}}}
$$

In eq $1, C_{\mathrm{i}}^{\mathrm{LS}} V_{\mathrm{i}}^{\mathrm{LS}}$ is the initial mass of arsenite in the lumen solution (total arsenic); $C_{\mathrm{f}}^{\mathrm{LS}} V_{\mathrm{f}}^{\mathrm{LS}}$ is the mass of arsenite in the 

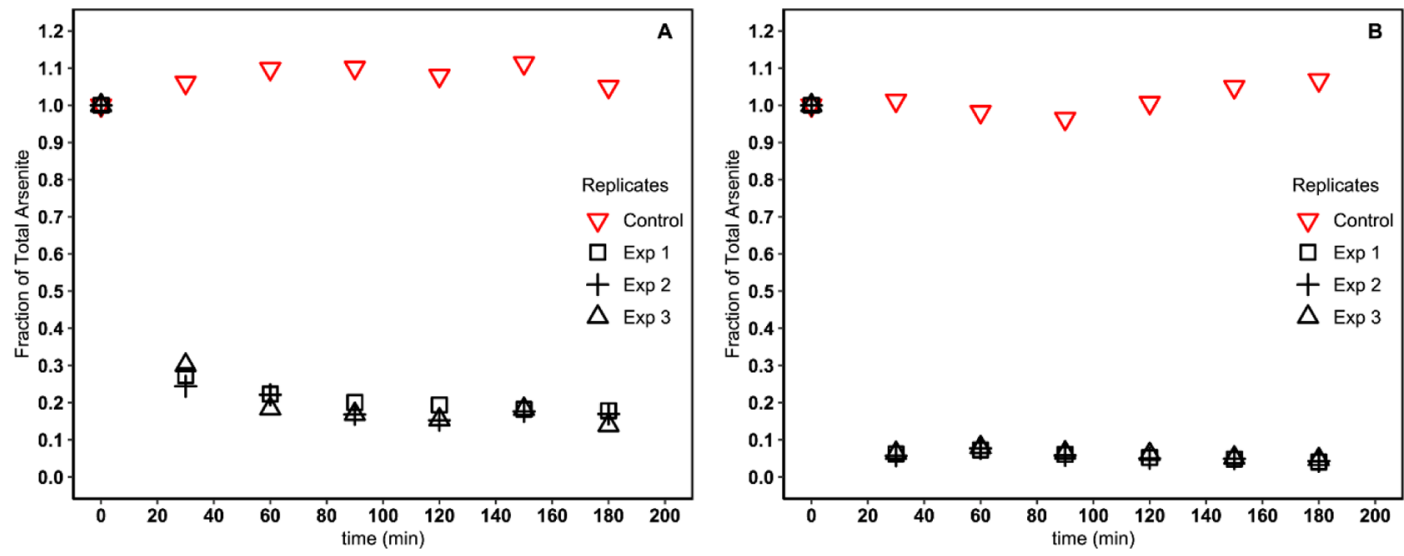

Figure 7. Removal of arsenite in batch experiments over time for 1.25 (A) and $2.68 \mathrm{~g} / \mathrm{L}$ (B) adsorbent loadings. The amount of arsenite remaining in solution is presented as a mass fraction of total arsenic.

lumen solution at the end of the experiment; $V_{\mathrm{s}} \sum_{n=1}^{m-n \geq 1} C_{n}^{\mathrm{SF}}$ is the mass of arsenite sampled from the service fluid during the runtime; $C_{m}^{\mathrm{SF}} V_{\mathrm{f}}^{\mathrm{SF}}$ is the residual mass of arsenite in the service fluid at the end of the experiment; and $m$ is the total number of samples taken from the service fluid. Thus, removal efficiency for each loading $\left(\mathrm{RE}_{\text {sys }}\right)$ was quantified by the mass fraction of the adsorbed arsenite and was calculated at 67 and $91 \%$ for 1.22 and $2.61 \mathrm{~g} / \mathrm{L}$ adsorbent loadings, respectively. The 1.22 $\mathrm{g} / \mathrm{L}$ loading with $20.2 \mathrm{mg}$ of total arsenite had a lower removal efficiency than the $2.61 \mathrm{~g} / \mathrm{L}$ adsorbent loading with $25.8 \mathrm{mg}$ of total arsenite, suggesting that a smaller total arsenic to $\mathrm{Fh}$ ratio results in better removal.

Changes in $\mathrm{pH}$ of the system over the course of the treatment process are shown in Figure 6A. The introduction of Fh into the service solution caused a sudden drop in $\mathrm{pH}$ for both loadings. Fh has been reported to accumulate protons when exposed to air through a series of reactions as carbon dioxide adsorbs onto its bound water layer. ${ }^{32-34}$ This likely occurred during the final drying stage of the synthetic process and is indicated by the FTIR spectrum in Figure 3. The increased surface acidity transferred into the service fluid during the addition of $\mathrm{Fh}$ and likely caused a $\mathrm{pH}$ drop proportional to the loading. As treatment progressed, adsorption of arsenite onto $\mathrm{Fh}$ caused the increase in $\mathrm{pH}$ for both loadings. It has been reported that arsenite adsorbs onto Fh through several possible adsorption reactions, resulting in either the net release of $\mathrm{H}^{+}$or $\mathrm{OH}^{-}$depending on the operating $\mathrm{pH}^{36}$ The $2.61 \mathrm{~g} / \mathrm{L}$ loading had a smaller $\mathrm{pH}$ recovery than the $1.22 \mathrm{~g} / \mathrm{L}$ loading because of the higher initial acidity produced by excess $\mathrm{Fh}$.

Figure $6 \mathrm{~B}$ shows the variance in Eh measurements of the system for both loadings. The redox potential is influenced by changes in $\mathrm{pH}$ according to the Nernst equation, and the two parameters have an inverse relationship. The steep drop in $\mathrm{pH}$ followed by the introduction of $\mathrm{Fh}$ was mirrored by a corresponding spike in $\mathrm{Eh}$, and the subsequent $\mathrm{pH}$ recovery throughout the remaining runtime was mirrored by a decrease in Eh. For each loading, the extent of change in Eh was also proportional to the change in $\mathrm{pH}$, with the $2.61 \mathrm{~g} / \mathrm{L}$ loading having a larger drop in $\mathrm{pH}$ and a larger spike in Eh in comparison to the $1.21 \mathrm{~g} / \mathrm{L}$ loading.

Batch Adsorption. For batch adsorption experiments, Fh was added to beakers containing arsenite solution and stirred while samples were taken over time. Figure $7 \mathrm{~A}, \mathrm{~B}$ shows the removal of arsenite with 1.25 and $2.68 \mathrm{~g} / \mathrm{L}$ loadings. The amount of arsenite remaining in the solution at each point in time is presented as a mass fraction of the total arsenite introduced initially. The amount of arsenite adsorbed onto Fh is calculated using a mass balance on the total arsenite according to eq 2 as follows: $C_{\mathrm{i}} V_{\mathrm{i}}$ is the initial mass of arsenite in solution; $V_{\mathrm{s}} \sum_{n=1}^{m-n \geq 1} C_{n}$ is the accumulated mass removed from sampling; $C_{m} V_{\mathrm{f}}$ is the final mass remaining in solution; and $m$ is the total number of samples.

$$
\mathrm{RE}_{\text {batch }}=\frac{C_{\mathrm{i}} V_{\mathrm{i}}-\left(V_{\mathrm{s}} \sum_{n=1}^{m-n \geq 1} C_{n}+C_{m} V_{\mathrm{f}}\right)}{C_{\mathrm{i}} V_{i}}
$$

In the experimental replicates, most of the arsenite was removed within $30 \mathrm{~min}$. Additional reaction time minimally increased the overall removal. For the $1.25 \mathrm{~g} / \mathrm{L}$ loading, Table 1 shows that on average, $73 \%$ of the total arsenite in solution

Table 1. Accumulated Removal of As Over Time for $1.25 \mathrm{~g} /$ L Fh Loading

\begin{tabular}{cccccccc} 
& \multicolumn{3}{c}{ fraction As removed } & & \multicolumn{2}{c}{ statistics } \\
\cline { 2 - 5 }$\Delta t(\min )$ & C & E1 & E2 & E3 & & E avg & E SD \\
30 & -0.061 & 0.727 & 0.756 & 0.699 & & 0.727 & 0.029 \\
90 & -0.101 & 0.784 & 0.816 & 0.814 & & 0.804 & 0.018 \\
180 & -0.050 & 0.804 & 0.814 & 0.841 & & 0.820 & 0.019
\end{tabular}

was removed within $30 \mathrm{~min}$ and $82 \%$ within $3 \mathrm{~h}$. Thus, $89 \%$ of the arsenite was removed within that 30 min mark, leaving $11 \%$ to be adsorbed in $2.5 \mathrm{~h}$. For the $2.68 \mathrm{~g} / \mathrm{L}$ loading, Table 2 shows that on average, $94 \%$ of the total arsenite and all arsenite that would be removed was removed within $30 \mathrm{~min}$. Raven et al., 1998 (ref 20), also showed similar adsorption behavior, having high initial removal in less than $30 \mathrm{~min}$ in $2 \mathrm{~g} / \mathrm{L} \mathrm{Fh}$ suspensions containing 40.01 and $2000.4 \mathrm{mg} / \mathrm{L}$ arsenite at $\mathrm{pH}$

Table 2. Accumulated Removal of As Over Time for $2.68 \mathrm{~g} /$ L Fh Loading

\begin{tabular}{crcccccc} 
& \multicolumn{3}{c}{ fraction As removed } & & \multicolumn{2}{c}{ statistics } \\
\cline { 2 - 4 }$\Delta t(\min )$ & $\mathrm{C}$ & $\mathrm{E} 1$ & $\mathrm{E} 2$ & $\mathrm{E} 3$ & & E avg & E SD \\
30 & -0.013 & 0.938 & 0.943 & 0.936 & & 0.939 & 0.004 \\
90 & 0.036 & 0.923 & 0.925 & 0.918 & & 0.922 & 0.004 \\
180 & -0.068 & 0.941 & 0.939 & 0.934 & & 0.938 & 0.004
\end{tabular}



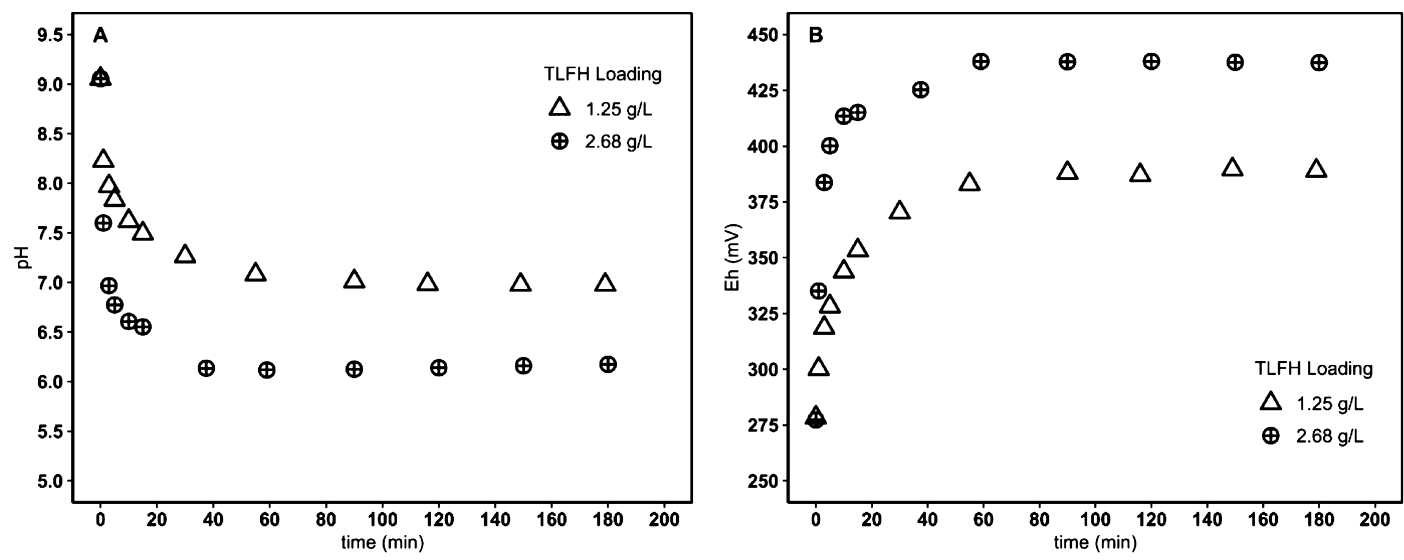

Figure 8. Changes in $\mathrm{pH}(\mathrm{A})$ and $\mathrm{Eh}(\mathrm{B})$ of batch arsenic removal with 1.25 and $2.68 \mathrm{~g} / \mathrm{L}$ Fh loadings.

9.2. Li et al., 2011 ( $r e f$ 22), also reported 90\% adsorption within $1 \mathrm{~h}$ using a $0.25 \mathrm{~g} / \mathrm{L}$ Fh loading in a $5 \mathrm{mg} / \mathrm{L}$ arsenite solution at $\mathrm{pH} \mathrm{7.} \mathrm{Zhu} \mathrm{et} \mathrm{al.,} 2011$ (ref 23), attributed this behavior to a biphasic sorption process. Working with a $5 \mathrm{~g} / \mathrm{L}$ Fh loading in a $525 \mathrm{mg} / \mathrm{L}$ arsenite solution at $\mathrm{pH} \mathrm{6}$, it was noted that a fast, initial sorption process occurred within 0.167 h $(10 \mathrm{~min})$, followed by a slower secondary sorption process. Overall, these prior reports indicate that the adsorption process of arsenite to Fh is fast (Table S3). Rapid adsorption can have a profound effect on treatment processes, minimizing both the required contact time (hydraulic retention time) and the size of treatment systems (footprint).

Variation of $\mathrm{pH}$ and Eh over time for the two Fh loadings is shown in Figure 8A,B. As observed in the system, there is large drop in $\mathrm{pH}$ and a large increase in Eh. The changes in $\mathrm{pH}$ and Eh were inversely related and in proportion to the loading of Fh. Unlike the dialysis system, the overall change for both parameters was smoother and occurred over a longer period without a recovery. This is likely a combined effect from the introduction of $\mathrm{Fh}$ protons into water and from arsenite adsorption onto Fh. This contention is further supported by other experiments from our laboratory (Figure S1) where 1.25 $\mathrm{g} / \mathrm{L}$ Fh was added to a solution imitating the ionic strength and $\mathrm{pH}$ of the batch reactions without arsenite. In this circumstance, the $\mathrm{pH}$ dropped sharply and plateaued within 5 $\min$.

Comparison of Arsenite Removal by Dialysis to Batch Adsorption. Performance of the dialysis-based system in comparison to batch adsorption was dependent on the Fh loading and the behavior of the material over the treatment process. In both the dialysis system and batch adsorption, higher Fh loadings resulted in greater removal efficiencies, but batch adsorption was overall more efficient than the system. At the lower $1.22 \mathrm{~g} / \mathrm{L}$ adsorbent loading, the dialysis system had less total arsenite in contrast to its batch counterpart, yet it removed only $67 \%$ of the total arsenite in comparison to the $82 \%$ average removed by batch adsorption. At the higher 2.61 $\mathrm{g} / \mathrm{L}$ adsorbent loading, where the total arsenite was similar in the dialysis system and in the batch replicates, the system removed $91 \%$ of the total arsenite in comparison to the average $94 \%$ removed by batch adsorption. Most of the arsenite passed from the membrane lumen into the service fluid within the treatment period according to Figure 5, and given that batch experiments showed adsorption to be fast, differences in performance cannot be attributed to the unavailability of arsenite for adsorption or an insufficient treatment time.
Differences are attributed to changes in dispersion of Fh over time within the treatment mixtures. Figure 9A shows that Fh in

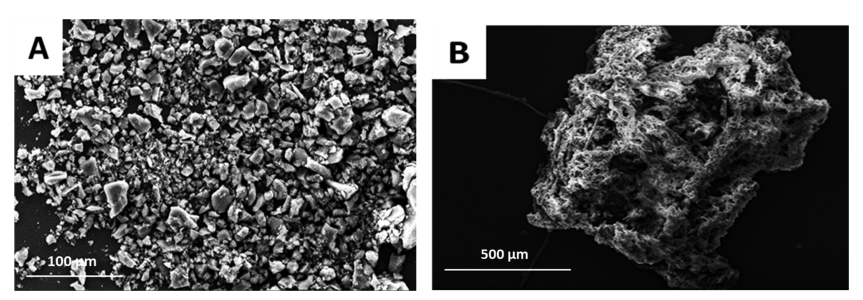

Figure 9. SEM of Fh particles before (A) and after (B) use in the dialysis system for arsenite removal.

both batch and dialysis system processes is introduced as a distribution of particles generally well below $100 \mu \mathrm{m}$ in cross section. These particles disperse in solution into a fine colloidal suspension that should facilitate the fast adsorption of arsenite. However, the adsorbent in the dialysis system undergoes noticeable physical changes over the course of the treatment process. As seen in Figure 9B, particles aggregate to a large size and can lodge in rough surfaces within the body of the system. Dispersion of the adsorbent is reduced and is easily noticed by an increase in translucency of the service fluid. This phenomenon likely adversely affected the removal efficiency of the $1.22 \mathrm{~g} / \mathrm{L}$ system loading. The $2.61 \mathrm{~g} / \mathrm{L}$ system loading was able to maintain a high removal because of the excess Fh present that can counteract the effect of particle aggregation. The addition of excess adsorbent, however, underutilizes the material's adsorption capacity. The adsorption capacity of $\mathrm{Fh}$ can be calculated as a weight percent by taking the ratio between the concentration of arsenic adsorbed and the adsorbent loading. For the 1.22 and $2.61 \mathrm{~g} / \mathrm{L}$ system loadings, the adsorption capacity is 3.9 and $3.0 \% \mathrm{w} / \mathrm{w}$, respectively, in comparison to 6.5 and $3.2 \% \mathrm{w} / \mathrm{w}$ for batch adsorption. The adsorption capacity for $\mathrm{Fh}$ in the literature has been reported between 2 and 20\% (adapted as w/w) and is heavily dependent on experimental conditions (Table S3).

Dialytic System Implications and Design Improvements. The dialysis system has demonstrated successful removal of arsenite using nano-adsorbents. However, several modifications are needed to improve the performance and overall reliability for industrial applications. As previously mentioned, nanoparticles aggregate over time to sizes several orders of magnitude higher than the original particle sizes (Figure 8 ). The physical structure of the system and formation 
of eddies entrap the adsorbent particles into crevices and uneven surfaces and immobilize a fraction of the adsorbent. Entrapment could be mitigated in part with improved fluidic design but aggregation must also be addressed. One contributing factor to aggregation may be the increased collision frequency between nanoparticles due to flow shear forces. Flume experiments with $\mathrm{CeO}_{2}$ nanoparticles have demonstrated that shear forces during flow increase $z$-average particle size over time as analyzed by dynamic light scattering (DLS). ${ }^{37}$ Nanomaterials also have a natural tendency to aggregate because of the instability of their surface charges, and the high ionic strength service fluid may enhance this effect. $^{38,39}$ Liu et al., 2019 (ref 41), investigated the aggregation of the more crystalline six-line $\mathrm{Fh}$ (diameter $\sim 6 \mathrm{~nm}$ ) using DLS and showed that the hydrodynamic radius increases more dramatically over time in higher ionic strength conditions near neutral $\mathrm{pH}$. High salt solutions transmit ion charges, reduce electrostatic repulsion, and lower the energy barrier needed for collisions to form aggregates. ${ }^{40}$ This suggests that reducing the ionic strength may serve to minimize aggregation, but may impose limitations on the operating parameters under realworld conditions. Some studies suggest that the incorporation of chemical additives with strongly coordinating ligands, such as organic acids, into adsorbent mixtures can suppress aggregation. ${ }^{41,42}$ Maintaining a low ionic strength may limit additives that can be added to improve performance of the nano-adsorbents and requires that the service solution be protected from accumulating high concentrations of multivalent metals or other treated species during operation. Even accounting for these considerations, extended system runtimes result in a higher number of particle collisions, which may nonetheless counteract these adjustments. However, in an improved system, nano-adsorbents that are exhausted (saturated with contaminants) over a longer contact time can be replaced before aggregation becomes detrimental to performance. The most significant advantage of the proposed design is that nano-adsorbents are never in direct contact with treated or untreated water and can be easily removed and replaced.

\section{CONCLUSIONS}

We demonstrated the application of the hemodialyzer (renal dialysis) design in using nano-adsorbents for water purification. Here, we used two-line Fh for the removal of arsenite. These experiments have served as a proof of concept for a new approach for applying nanomaterials in fluidic purification. Traditional batch experiments were also conducted to assess the removal efficiency, measure changes in $\mathrm{Eh}$ and $\mathrm{pH}$, and compare the results to those obtained from the proposed system. Finally, Eh and $\mathrm{pH}$ values, at equilibrium, are approximately close for both experiments; however, initial Eh and $\mathrm{pH}$ changes are dissimilar. This is an important observation that should be considered in designing an industrial-scale purification system with a short hydraulic retention time. A comparison of the two methods showed that for similar adsorbent loadings over the same runtime, the system removed 67 and $91 \%$ of arsenite, while the batch method adsorbed 82 and $94 \%$. Future studies improving on the proposed design should focus on preventing eddy formation and increasing the mass transfer rate, which can increase the removal efficiency and lifetime of nano-adsorbents and reduce the required hydraulic retention time.

\section{MATERIALS AND METHODS}

Synthesis and Characterization Methods of Fh. Fh was synthesized using the SDM reported by Smith et al. (2012). ${ }^{26}$ Briefly, a 1:3 molar ratio of $\mathrm{Fe}\left(\mathrm{NO}_{3}\right) \cdot 9 \mathrm{H}_{2} \mathrm{O}$ (ACS grade, Acros) and $\mathrm{NH}_{4} \mathrm{NO}_{3}$ (98\%, Acros) was continuously ground together using a mortar and pestle until bubbling stopped, and a dark brown precipitate formed. The precipitate was dried at $100{ }^{\circ} \mathrm{C}$ for $24 \mathrm{~h}$, vacuum filtered, rinsed with small volumes of reagent grade water, and dried again for another 24 h. The material was ground to a fine dark brown powder using a mortar and pestle before analysis and use in experiments. All experiments were performed using the same single batch of Fh.

$\mathrm{X}$-ray diffractograms for $\mathrm{Fh}$ were obtained using a Bruker D8 ADVANCE diffractometer operating at $40 \mathrm{kV}$ and $40 \mathrm{~mA}$ using $\mathrm{Cu} \mathrm{K} \alpha$ radiation $(\lambda=1.5406)$. The powder samples were scanned from 20 to $80^{\circ} 2 \theta$ in $0.02^{\circ}$ increments with a $1 \mathrm{~s}$ dwell time. The FTIR absorbance spectrum was obtained using a PerkinElmer ATR-FTIR 100 spectrometer from 4000 to 650 $\mathrm{cm}^{-1}$. TEM micrographs were taken using a JEOL JEM-1400 microscope. SEM micrographs were taken using an FEI Quanta 450 FEG microscope operating at $30 \mathrm{kV}$. The surface area of Fh was obtained using a Micrometrics ASAP 2020 analyzer with degassing at $100{ }^{\circ} \mathrm{C}$ for $4 \mathrm{~h}$ and calculated using the BET method.

Dialysis System Experiments. The dialysis system was set up as follows. A $100 \mathrm{kDa}$ dialysis tube was clamped vertically to a ring stand. A $600 \mathrm{~mL}$ beaker containing a stir bar was placed atop a stirrer. Size $15 \mathrm{C}$-flex tubing was fitted into a Cole-Parmer Masterflex L/S peristaltic pump with a highperformance pump head. One end of the tubing was fixed to the bottom inlet of the dialysis system, while the other end of the tube was placed inside the beaker. Another piece of tubing was fixed to the top outlet of the dialysis tube, and its free end was placed inside the beaker as well. Oxidation-reduction potential and $\mathrm{pH}$ probes were fixed from the ring stand inside the beaker to track changes in $\mathrm{Eh}$ and $\mathrm{pH}$ over time.

In preparation for use, the dialysis membrane was primed to remove glycerin. A $10 \%$ ethanol solution was used to both hand-fill the lumen of the membrane and to pump solution continuously through the outer body for $15 \mathrm{~min}$. Similarly, several rinses with deionized water were used to remove traces of ethanol from the membrane.

To start each experiment, $37 \mathrm{~mL}$ of $\mathrm{pH} 9.05$ arsenite solution-prepared from $\mathrm{As}_{2} \mathrm{O}_{3}$ powder-was added by hand into the lumen of the membrane. A sample from the excess of this solution was preserved with concentrated nitric acid and later analyzed to determine the initial arsenic concertation. Then, a $250 \mathrm{~mL}$ service solution containing a $\mathrm{NaNO}_{3}$ ionic strength of 0.25 and a $\mathrm{pH}$ of 9.05 was prepared in the $600 \mathrm{~mL}$ beaker. An initial $5 \mathrm{~mL}$ sample was taken, and $\mathrm{Fh}$ was added into the beaker to attain 1.22 or $2.61 \mathrm{~g} / \mathrm{L}$ loading (by total system volume). The service solution was continuously stirred, slowly pumped from the bottom to the top to fill the system, and then set at a flow rate of $300 \mathrm{~mL} / \mathrm{min}$. Over the course of $3 \mathrm{~h}$, samples were taken from the beaker, filtered through a $0.45 \mu \mathrm{m}$ PTFE syringe filter, acidified with concentrated nitric acid to a $\mathrm{pH}$ below 2, and refrigerated for preservation. Changes in $\mathrm{pH}$ and $\mathrm{Eh}$ of the service fluid were also tracked over the runtime of each experiment. At the end of the experiment, a sample was taken from the lumen of the membrane to determine the final arsenite concentration after treatment. Arsenite concentration in samples was analyzed 
using a Thermo Scientific iCAP Q inductively coupled plasma mass spectrometer operated by Alpha Analytical, Inc. following EPA Method 200.8 for total arsenic analysis. Solutions in the membrane lumen had initial arsenite concentrations of 545.5 and $679.5 \mathrm{mg} / \mathrm{L}$ for the 1.22 and $2.61 \mathrm{~g} / \mathrm{L} \mathrm{Fh}$ loadings, respectively.

Batch Experiments. Arsenite adsorption by $\mathrm{Fh}$ was evaluated with 1.25 and $2.68 \mathrm{~g} / \mathrm{L}$ Fh loadings in two separate experiments. In each case, four $280 \mathrm{~mL}$ arsenite solutionsprepared from $\mathrm{As}_{2} \mathrm{O}_{3}$ powder-were adjusted to an ionic strength of 0.22 using $\mathrm{NaNO}_{3}$ and set to an initial $\mathrm{pH}$ of 9.05 using $\mathrm{NaOH}$ and $\mathrm{HNO}_{3}$. An initial $5 \mathrm{~mL}$ sample was taken from each solution, quickly filtered through a $0.45 \mu \mathrm{m}$ PTFE syringe filter, acidified with concentrated nitric acid to a $\mathrm{pH}$ below 2, and refrigerated for preservation. Fh was introduced into three of the solutions, while the fourth remained as a control. The solutions were continuously stirred atop a multistirrer at $600 \mathrm{rpm}$. Over the course of $3 \mathrm{~h}$, the solutions were sampled every half hour and samples were processed as described above. In between sampling periods, the solutions were covered to prevent evaporation. Changes in $\mathrm{pH}$ and $\mathrm{Eh}$ of one of the noncontrol solutions were also tracked over the runtime of each experiment using $\mathrm{pH}$ and redox probes. Solutions with the $1.25 \mathrm{~g} / \mathrm{L}$ adsorbent loading had initial arsenic concentrations of 74.4 and $111.6 \mathrm{mg} / \mathrm{L}$ and the control system had an initial arsenic concentration of $65.6 \mathrm{mg} / \mathrm{L}$. Solutions with the $2.68 \mathrm{~g} / \mathrm{L}$ adsorbent loading had initial arsenic concentrations of $88.4,91.5$, and $96.1 \mathrm{mg} / \mathrm{L}$, and the control system initial arsenite concentration was $92.7 \mathrm{mg} / \mathrm{L}$.

\section{ASSOCIATED CONTENT}

\section{SI Supporting Information}

The Supporting Information is available free of charge at https://pubs.acs.org/doi/10.1021/acsomega.9b04121.

Fh BET SA measurements, Fh-induced drop in $\mathrm{pH}$, and As(III)-Fh batch adsorption profile at environmental $\mathrm{pH}$ (PDF)

\section{AUTHOR INFORMATION}

\section{Corresponding Author}

Rouzbeh Tehrani - Department of Civil and Environmental Engineering, Temple University, Philadelphia, Pennsylvania 19122, United States; 이이. orcid.org/0000-0002-5989-7049; Email: r.tehrani@temple.edu

\section{Authors}

Kyriakos Atmatzidis - Department of Civil and Environmental Engineering, Temple University, Philadelphia, Pennsylvania 19122, United States

Farbod Alimohammadi - Department of Chemistry, Temple University, Philadelphia, Pennsylvania 19122, United States

Daniel R. Strongin - Department of Chemistry, Temple University, Philadelphia, Pennsylvania 19122, United States; () orcid.org/0000-0002-1776-5574

Complete contact information is available at:

https://pubs.acs.org/10.1021/acsomega.9b04121

\section{Notes}

The authors declare no competing financial interest.

\section{ACKNOWLEDGMENTS}

This work was supported by Temple University College of Engineering.

\section{REFERENCES}

(1) Santhosh, C.; Velmurugan, V.; Jacob, G.; Jeong, S. K.; Grace, A. N.; Bhatnagar, A. Role of nanomaterials in water treatment applications: A review. Chem. Eng. J. 2016, 306, 1116-1137.

(2) Westerhoff, P.; Alvarez, P.; Li, Q.; Gardea-Torresdey, J.; Zimmerman, J. Overcoming implementation barriers for nanotechnology in drinking water treatment. Environ. Sci.: Nano 2016, 3, $1241-1253$

(3) Adeleye, A. S.; Conway, J. R.; Garner, K.; Huang, Y.; Su, Y.; Keller, A. A. Engineered nanomaterials for water treatment and remediation: Costs, benefits, and applicability. Chem. Eng. J. 2016, 286, 640-662.

(4) Ding, W.; He, L.; Zhao, G.; Zhang, H.; Shu, Z.; Gao, D. Double porous media model for mass transfer of hemodialyzers. Int. J. Heat Mass Transfer 2004, 47, 4849-4855.

(5) Ding, W.; Li, W.; Sun, S.; Zhou, X.; Hardy, P. A.; Ahmad, S.; Gao, D. Three-Dimensional Simulation of Mass Transfer in Artificial Kidneys. Artif. Organs 2015, 39, E79-E89.

(6) Chung, J.-Y.; Yu, S.-D.; Hong, Y.-S. Environmental source of arsenic exposure. J. Prev. Med. Public Heal. 2014, 47, 253-257.

(7) Bhattacharya, P.; Jacks, G.; Frisbie, S.; Euan, S.; Naidu, R.; Sarkar, B. Arsenic in the Environment: A Global Perspective. In Heavy Metals In The Environment; Sarkar, B., Ed.; CRC Press: New York, 2002; pp 147-155.

(8) Gomez-Caminero, A.; Howe, P.; Hughes, M.; Kenyon, E.; Lewis, D.; Moore, M.; Ng, J.; Aitio, A.; Becking, G. Arsenic and Arsenic Compounds; Ng, J., Ed.; WHO: Geneva, 2001.

(9) IARC Working Group. Arsenic, Metals, Fibres, and Dusts: A Review of Human Carcinogens, 2012; Vol. 100C, pp 41-93.

(10) Chou, S.; Harper, C.; Ingerman, L.; Llados, F.; Colman, J.; Chappell, L.; Osier, M.; Odin, M.; Sage, G. Toxicological Profile for Arsenic; ATSDR: Atlanta, 2001.

(11) Bhattacharya, P.; Welch, A. H.; Stollenwerk, K. G.; McLaughlin, M. J.; Bundschuh, J.; Panaullah, G. Arsenic in the environment: Biology and Chemistry. Sci. Total Environ. 2007, 379, 109-120.

(12) Jain, C. K.; Ali, I. Arsenic: Occurrence, toxicity and speciation techniques. Water Res. 2000, 34, 4304-4312.

(13) Korte, N. E.; Fernando, Q. A review of arsenic (III) in groundwater. Crit. Rev. Environ. Control 1991, 21, 1-39.

(14) Bowell, R. J. Sorption of arsenic by iron oxides and oxyhydroxides in soils. Appl. Geochem. 1994, 9, 279-286.

(15) Dixit, S.; Hering, J. G. Comparison of $\operatorname{arsenic}(V)$ and arsenic(III) sorption onto iron oxide minerals: Implications for arsenic mobility. Environ. Sci. Technol. 2003, 37, 4182-4189.

(16) Gimenez, J.; Martinez, M.; Depablo, J.; Rovira, M.; Duro, L. Arsenic sorption onto natural hematite, magnetite, and goethite. $J$. Hazard. Mater. 2007, 141, 575-580.

(17) Aredes, S.; Klein, B.; Pawlik, M. The removal of arsenic from water using natural iron oxide minerals. J. Cleaner Prod. 2013, 60, 7176.

(18) Schwertmann, U.; Friedl, J.; Stanjek, H. From Fe(III) Ions to Ferrihydrite and then to Hematite. J. Colloid Interface Sci. 1999, 209, 215-223.

(19) Das, S.; Hendry, M. J.; Essilfie-Dughan, J. Transformation of two-line ferrihydrite to goethite and hematite as a function of $\mathrm{pH}$ and temperature. Environ. Sci. Technol. 2011, 45, 268-275.

(20) Raven, K. P.; Jain, A.; Loeppert, R. H. Arsenite and arsenate adsorption on ferrihydrite: Kinetics, equilibrium, and adsorption envelopes. Environ. Sci. Technol. 1998, 32, 344-349.

(21) Schwertmann, U.; Cornell, R. M. Ferrihydrite. Iron Oxides in the Laboratory: Preparation and Characterization, 2nd ed.; Wiley-VCH: Weinheim, 2000; pp 103-110. 
(22) Li, Z.; Zhang, T.; Li, K. One-step synthesis of mesoporous twoline ferrihydrite for effective elimination of arsenic contaminants from natural water. Dalton Trans. 2011, 40, 2062-2066.

(23) Zhu, J.; Pigna, M.; Cozzolino, V.; Caporale, A. G.; Violante, A. Sorption of arsenite and arsenate on ferrihydrite: Effect of organic and inorganic ligands. J. Hazard. Mater. 2011, 189, 564-571.

(24) Kim, S.-O.; Chun Lee, W.; Goo Cho, H.; Lee, B.-T.; Lee, P.-K.; Hee Choi, S. Equilibria, kinetics, and spectroscopic analyses on the uptake of aqueous arsenite by two-line ferrihydrite. Environ. Technol. 2014, 35, 251-261.

(25) Ona-Nguema, G.; Morin, G.; Juillot, F.; Calas, G.; Brown, G. E. EXAFS analysis of arsenite adsorption onto two-line ferrihydrite, hematite, goethite, and lepidocrocite. Environ. Sci. Technol. 2005, 39, 9147-9155.

(26) Smith, S. J.; Page, K.; Kim, H.; Campbell, B. J.; Boerio-Goates, J.; Woodfield, B. F. Novel synthesis and structural analysis of ferrihydrite. Inorg. Chem. 2012, 51, 6421-6424.

(27) Jia, Y.; Xu, L.; Fang, Z.; Demopoulos, G. P. Observation of surface precipitation of arsenate on ferrihydrite. Environ. Sci. Technol. 2006, 40, 3248-3253.

(28) Villacís García, M.; Ugalde Arzate, M.; Vaca Escobar, K.; Villalobos, M.; Zanella, R.; Martínez Villegas, N.; Luis Potosí, S. Laboratory synthesis of goethite and ferrihydrite of controlled particle sizes. Bol. Soc. Geol. Mex. 2015, 67, 433-446.

(29) Zhu, B.-S.; Jia, Y.; Jin, Z.; Sun, B.; Luo, T.; Kong, L.-T.; Liu, J.$\mathrm{H}$. A facile precipitation synthesis of mesoporous 2-line ferrihydrite with good fluoride removal properties. RSC Adv. 2015, 5, 8438984397.

(30) Jianmin, Z.; Huggins, F. E.; Zhen, F.; Huffman, G. P. Ferrihydrite: Surface structure and its effects on phase transformation. Clays Clay Miner. 1994, 42, 737-746.

(31) Jiang, X.; Peng, C.; Fu, D.; Chen, Z.; Shen, L.; Li, Q.; Ouyang, T.; Wang, Y. Removal of arsenate by ferrihydrite via surface complexation and surface precipitation. Appl. Surf. Sci. 2015, 353, $1087-1094$.

(32) Baltrusaitis, J.; Schuttlefield, J. D.; Zeitler, E.; Jensen, J. H.; Grassian, V. H. Surface reactions of carbon dioxide at the adsorbed water-oxide interface. J. Phys. Chem. C 2007, 111, 14870-14880.

(33) Hausner, D. B.; Bhandari, N.; Pierre-Louis, A.-M.; Kubicki, J. D.; Strongin, D. R. Ferrihydrite reactivity toward carbon dioxide. J. Colloid Interface Sci. 2009, 337, 492-500.

(34) Baltrusaitis, J.; Schuttlefield, J.; Zeitler, E.; Grassian, V. H. Carbon dioxide adsorption on oxide nanoparticle surfaces. Chem. Eng. J. 2011, 170, 471-481.

(35) Hakim, A.; Marliza, T. S.; Abu Tahari, N. M.; Wan Isahak, R. W. N.; Yusop, R. M.; Mohamed Hisham, W. M.; Yarmo, A. M. Studies on CO2 Adsorption and Desorption Properties from Various Types of Iron Oxides (FeO, Fe2O3, and $\mathrm{Fe} 3 \mathrm{O} 4)$. Ind. Eng. Chem. Res. 2016, 55, 7888-7897.

(36) Jain, A.; Raven, K. P.; Loeppert, R. H. Arsenite and arsenate adsorption on ferrihydrite: Surface charge reduction and net $\mathrm{OH}$ release stoichiometry. Environ. Sci. Technol. 1999, 33, 1179-1184.

(37) Lv, B.; Wang, C.; Hou, J.; Wang, P.; Miao, L.; You, G.; Yang, Y.; Xu, Y.; Zhang, M.; Ci, H. Towards a better understanding on aggregation behavior of $\mathrm{CeO} 2$ nanoparticles in different natural waters under flow disturbance. J. Hazard. Mater. 2018, 343, 235-244.

(38) Zhang, Y.; Zhu, C.; Liu, F.; Yuan, Y.; Wu, H.; Li, A. Effects of ionic strength on removal of toxic pollutants from aqueous media with multifarious adsorbents: A review. Sci. Total Environ. 2019, 646, 265279.

(39) Mercer, K. L.; Tobiason, J. E. Removal of arsenic from high ionic strength solutions: Effects of ionic strength, $\mathrm{pH}$, and preformed versus in situ formed HFO. Environ. Sci. Technol. 2008, 42, 37973802.

(40) Liu, J.; Louie, S. M.; Pham, C.; Dai, C.; Liang, D.; Hu, Y. Aggregation of ferrihydrite nanoparticles: Effects of $\mathrm{pH}$, electrolytes,and organics. Environ. Res. 2019, 172, 552-560.
(41) Yuwono, V. M.; Burrows, N. D.; Soltis, J. A.; Anh Do, T.; Lee Penn, R. Aggregation of ferrihydrite nanoparticles in aqueous systems. Faraday Discuss. 2012, 159, 235-245.

(42) Angelico, R.; Ceglie, A.; He, J.-Z.; Liu, Y.-R.; Palumbo, G.; Colombo, C. Particle size, charge and colloidal stability of humic acids coprecipitated with ferrihydrite. Chemosphere 2014, 99, 239-247. 